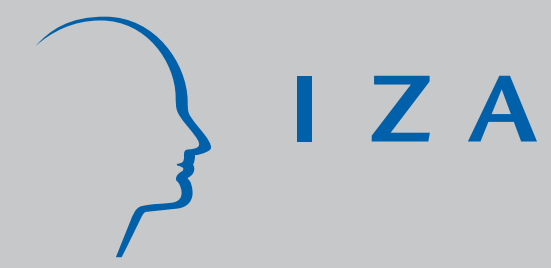

IZA DP No. 75

Adjustment Dynamics and the Natural Rate: An Account of UK Unemployment

\author{
Brian Henry \\ Marika Karanassou \\ Dennis J. Snower
}

December 1999 


\title{
Adjustment Dynamics and the Natural Rate: An Account of UK Unemployment
}

\author{
Brian Henry \\ Centre for Economic Forecasting, London Business School, London \\ Marika Karanassou \\ Department of Economics, Queen Mary and Westfield College, \\ University of London, London \\ Dennis J. Snower \\ Department of Economics, Birkbeck College, \\ University of London, London; CEPR and IZA
}

Discussion Paper No. 75
December 1999

\author{
IZA \\ P.O. Box 7240 \\ D-53072 Bonn \\ Germany \\ Tel.: +49-228-3894-0 \\ Fax: +49-228-3894-210 \\ Email: iza@iza.org
}

This Discussion Paper is issued within the framework of IZA's research area Mobility and Flexibility of Labor Markets. Any opinions expressed here are those of the author(s) and not those of the institute. Research disseminated by IZA may include views on policy, but the institute itself takes no institutional policy positions.

The Institute for the Study of Labor (IZA) in Bonn is a local and virtual international research center and a place of communication between science, politics and business. IZA is an independent, nonprofit limited liability company (Gesellschaft mit beschränkter Haftung) supported by the Deutsche Post AG. The center is associated with the University of Bonn and offers a stimulating research environment through its research networks, research support, and visitors and doctoral programs. IZA engages in (i) original and internationally competitive research in all fields of labor economics, (ii) development of policy concepts, and (iii) dissemination of research results and concepts to the interested public. The current research program deals with (1) mobility and flexibility of labor markets, (2) internationalization of labor markets and European integration, (3) the welfare state and labor markets, (4) labor markets in transition, (5) the future of work, (6) project evaluation and (7) general labor economics.

IZA Discussion Papers often represent preliminary work and are circulated to encourage discussion. Citation of such a paper should account for its provisional character. 
IZA Discussion Paper No. 75

December 1999

\section{ABSTRACT}

\section{Adjustment Dynamics and the Natural Rate: An Account of UK Unemployment ${ }^{*}$}

This paper challenges what is the standard account of UK unemployment, namely that the major swings in unemployment over the past 25 years are due predominantly to movements in the underlying empirical "natural rate of unemployment" (NRU). Our analysis suggests that the British NRU has remained reasonable stable through time and that the medium-run swings in unemployment are due, instead, to very prolonged after-effects of persistent (transitory but long-lasting) shocks. We argue that (a) past UK labour market shocks have prolonged after-effects on unemployment due to interactions among different lagged adjustment processes in the labour market, (b) many of the important shocks that have hit the UK labour market over the past 25 years have been persistent, and (c) the persistence of the shocks is complementary to the persistence of the lagged adjustment processes in generating movements of UK unemployment.

JEL Classification: J32, J60, J64, E30, E37

Keywords: Unemployment, natural rate hypothesis, labour markets, employment, adjustment costs

Dennis J. Snower

Department of Economics

Birkbeck College

University of London

7 Gresse Street

London W1P 2LL

Tel.: +441716316408

Email: Dsnower@econ.bbk.ac.uk

\footnotetext{
We are grateful for the insightful comments of an anonymous referee. SGB Henry acknowledges financial support from ESRC Grant No.L116251013 Macroeconomic modelling and policy analysis in a changing world. Dennis J. Snower acknowledges the financial support from the Leverhulme Grant on Unemployment Dynamics and Matching Workers with Jobs. This paper is part of a research project on Unemployment Dynamics conducted at IZA.
} 


\section{Introduction}

This paper challenges what is the standard account of UK unemployment, namely that the major swings in unemployment over the past 25 years are due predominantly to movements in the underlying "natural rate of unemployment" (NRU). In the empirical literature, the NRU is estimated as the unemployment rate at which there is no tendency for the unemployment rate to change, given the values of the exogenous variables in the labour market model. It has often been observed that UK unemployment, much like unemployment in most continental European countries, varies more between business cycles than within them. Whereas the variations within business cycles are often attributed to temporary shocks, the variations between business cycles are usually ascribed to changes in the empirical NRU.

In contrast to this dominant view, the analysis of this paper suggests that the NRU has remained reasonably stable across business cycles over the past three decades and that the medium-run swings in unemployment are due, instead, to very prolonged after-effects of persistent shocks. By "persistent" shocks, we mean ones that are transitory but long-lasting. They cover the middle ground between the standard "temporary" shocks (changes in exogenous variables lasting for one period of analysis) and "permanent" shocks (changes lasting forever) that are common in the literature. Our analysis of prolonged after-effects of shocks is a development of the "chain reaction theory" of unemployment, ${ }^{1}$ in which labour market shocks lead to a chain reaction of unemployment effects, working their way through a network of lagged adjustment processes. We believe that this approach is able to shed new light on unemployment movements not just in the UK, but in many other OECD countries as well.

Our analysis provides three highly interrelated explanations for the evolution of UK unemployment over the medium run (extending over several business cycles):

- The analysis indicates that given labour market shocks have prolonged aftereffects on unemployment, due to the interactions among different lagged adjustment processes in the labour market. These adjustment processes - affecting employment, wage setting, and labour force participation decisions - are shown to be complementary to one another in propagating the unemployment effects through time. ${ }^{2}$

\footnotetext{
${ }^{1}$ For a further description of this theory, see Karanassou and Snower (1998a,b) which examine how temporary and permanent shocks are mediated through the interactions of complementary lagged adjustment processes in the labour market. The present paper carries this analysis forward by examining the dynamic unemployment effects of persistent shocks and providing an account of UK unemployment on this basis.

${ }^{2}$ For example, a temporary drop in labour demand may have persistent effects on unemployment, since current employment depends on past employment due to labour turnover costs. Consequently, people who lose their jobs in a recession may wind up becoming long-term unemployed; and if these long-term unemployed have lower job-search intensities than the short-term unemployed, they will exert little downward pressure on wages, thereby making unemployment even more persistent.
} 
- We argue that many of the important shocks that have hit the UK labour market over the past 25 years (e.g. the oil price and tax rate shocks) have been persistent, but not permanent - often lasting for half a decade or more.

- We show that the persistence of the shocks is complementary to the persistence of the lagged adjustment processes in generating movements in unemployment.

In our analysis the interaction among different lagged adjustment processes, and between the network of adjustment processes (on the one hand) and the persistent shocks are responsible for much of the major swings in unemployment over the past few decades.

Our analysis has potentially important policy conclusions. Since the empirical models of the NRU associate the major swings in unemployment with changes in the natural rate, they imply that only policies that affect the natural rate - such as the level of unemployment benefits, union density, or tax rates - are able to influence the prominent movements of unemployment. However our analysis, by associating unemployment fluctuations with the prolonged after-effects of persistent shocks, implies that policies which influence the adjustment speeds of labour market decisions - such as job counselling, job security legislation, employment subsidies for the long-term unemployed $^{3}$ - may also have an important role to play in treating unemployment.

The paper is organized as follows. Section 2 summarizes our approach and describes its relation to the relevant literature. Section 3 presents a simple underlying theoretical framework of analysis. Section 4 describes our empirical model of the UK labour market. Section 5 examines the dynamic responses of the unemployment rate to temporary and persistent shocks in this context. Finally, Section 6 derives the empirical NRU for our model, and shows how persistent shocks drove the actual unemployment rate away from the natural rate for substantial periods of time.

\section{Our Approach and Its Relation to the Literature}

Our study is motivated by what we perceive to be difficulties in interpreting the movement of UK unemployment through the purview of the currently dominant theories of unemployment. In most empirical variants of the natural rate hypothesis, unemployment can be decomposed into two components: a natural rate at which unemployment is static (given the values of the exogenous variables) and short-run fluctuations around it. Since it is implausible to attribute the long swings of UK unemployment to short-run fluctuations, changes in the natural rate must, according to this story, be the driving force behind the major ups and downs of British unemployment. The

\footnotetext{
${ }^{3}$ These policies will, in general, also affect the long-run equilibrium unemployment rate, but this effect is quite distinct from the effect on speeds of adjustment. For example, job security legislation has an ambiguous effect on unemployment in the long-run (e.g. Bentolila and Bertola (1990), Bertola (1990), Bentolila and Saint-Paul (1994), Diaz and Snower (1996), Chen, Snower, and Zoega (1997)), but it unambiguously increases the inertia of employment.
} 
interpretational difficulty with this approach is that it is not easy to explain why the UK natural rate should have remained so high for much of the 1980s, despite the many labour market reforms of the Thatcher government and despite the fact that the 1980s were one of the UK's longest sustained booms of the postwar period. Nor is it easy to explain why the UK natural rate should have declined so precipitously in the late 1980s, only to rise equally rapidly in the early 1990s. Business cycle conditions doubtlessly tell part of the required story, but it is nevertheless puzzling that the UK natural rate should have responded so readily to these cyclical fluctuations since 1988, when it was so slow to respond to them in the first part of the 1980s.

Another possible explanation for the swings in UK unemployment lies in the hysteresis hypothesis, which asserts that short-run unemployment fluctuations automatically become transformed into long-run changes, since unemployment dynamics are characterized by a unit root. The difficulty with this approach is that hysteresis combined with random labour market shocks implies that unemployment follows a random walk, so that the unemployment rate hits $0 \%$ or $100 \%$ with certainty within a finite time period. In fact, however, UK unemployment rates have tended to remain within a relatively narrow band, lying between $2 \%$ and $12 \%$.

\subsection{Prolonged Effects of Labour Market Shocks}

This paper offers a different explanation. Focusing on the UK labour market, we argue that the empirical natural rate in this country has exhibited far greater stability than the actual unemployment rate over the past 25 years and that much of the low-frequency movements in unemployment are due to prolonged effects of persistent shocks.

Although persistence mechanisms which prolong the effects of labour market shocks have received much attention in the macroeconomic literature over the past decade, they are generally not put forward as an explanation for unemployment movements over the longer run (say, between 5 to 25 years). The reason is that in most empirical models ${ }^{4}$ that combine unemployment persistence with a natural rate of unemployment, much of the after-effect from temporary shocks disappears after 1-3 years. Within this context, unemployment persistence clearly cannot account for a gradual rise in unemployment over much longer time periods. A good number of contributors, however, have recognized the importance of persistence mechanisms in explaining the prolonged effects of labour demand shocks on European unemployment, but have not motivated these mechanisms in terms of interactions among different lagged adjustment processes. ${ }^{5}$

\footnotetext{
${ }^{4}$ See, for example, Blanchard and Summers (1986) and Layard, Nickell, and Jackman (1991, p.433 ff).

${ }^{5}$ Bean (1994) emphasises that "there seems to be an important role for propagation mechanisms that lead temporary shocks to have persistent effects on unemployment" (p.614). But he does not consider the interplay among such mechanisms; instead he stresses that "the most important persistence mechanism is in my view likely to hinge on the characteristics or behaviour of the unemployed"
} 
We will argue that the natural rate models greatly under-estimate the persistence in the unemployment effects of temporary labour market shocks, and that they significantly over-estimate the effect of these shocks on the long-run unemployment rate. On the other hand, we contend that the hysteresis models over-estimate the persistence in the unemployment effects of temporary shocks, and do not take sufficient account of the persistence of the shocks themselves.

Most of this existing empirical literature on unemployment persistence rests on highly aggregative models, predominantly single-equation unemployment autoregressions. This paper, by contrast, examines unemployment persistence in the context of a multi-equation model of labour demand, wage setting, and labour force participation. Each of these equations is characterized by lags which exert complementary influences on unemployment persistence.

In this context, temporary shocks give rise to a chain reaction of lagged adjustments, working their way through a network of largely complementary lagged effects. The resulting degree of unemployment persistence is much larger than that which can be captured in the single-equation unemployment autoregressions. Within this framework, we will provide an empirical account of UK unemployment which suggests that the long-run UK unemployment rate did not track the actual unemployment rate closely and that the prolonged divergences between the two can be explained in terms of persistent shocks working their way through a network of lagged adjustment processes.

\subsection{Persistent Shocks}

When the prevailing literature on natural rate of unemployment and hysteresis analyzes the persistent effects of labour market shocks, focus is predominantly on temporary shocks. In the standard hysteresis models, these temporary shocks are portrayed as responsible for all the observed unemployment movements. ${ }^{6}$ In the natural rate models of unemployment persistence, these temporary shocks are responsible for temporary (though possibly prolonged) variation of the actual unemployment rate around its natural rate.

We argue that the standard practice, in the latter models, of dividing labour market shocks into temporary ones (whose effects might persist) and permanent ones (whose effects are embodied in the long-run unemployment equilibrium) has led the prevailing literature to under-emphasize the role of shocks which are persistent (transitory but not permanent). Over the past 25 years, the labour markets of the UK and many other OECD countries have experienced some very powerful shocks of the persistent, but not permanent, variety: the oil price shocks of the mid-70s and early 80 s, the interest rate shocks of the late 80s and early 1990s, and tax rate shocks of the late 70s and early 80s, just to name a few prominent ones. Each of these shocks lasted

(Ibid).

\footnotetext{
${ }^{6}$ See, for example, Blanchard and Summers (1986).
} 
for periods of half a decade or more. It is these types of shocks that are the primary focus of our analysis.

In our labour market model, ${ }^{7}$ as in the standard natural rate models of unemployment persistence, there is a unique long-run equilibrium unemployment rate, depending on the long-run values of the model's exogenous variables. In this context, persistent shocks are not relevant to the long-run labour market equilibrium; ${ }^{8}$ but we show that when they work through a network of largely complementary lagged adjustment processes, they may drive the unemployment rate away from its long-run equilibrium for substantial periods of time.

Furthermore, as we will show, the dynamic unemployment effect of these persistent shocks depends strongly on where these shocks originate, viz, whether they are labour demand shocks, wage setting shocks, or labour force participation shocks.

\section{The Theoretical Framework}

We now consider a very simple theoretical framework for the analysis of labour market adjustment dynamics, which will provide the background for the empirical model of Section 4. The framework is only illustrative of some lagged adjustment processes occurring in labour demand, wage setting, and labour force participation decisions. Our analysis is in the spirit of recent theoretical models of aggregate labour market activity (e.g. Layard, Nickell and Jackman (1991), Lindbeck and Snower (1989), Nickell (1995), and Taylor (1979)).

We consider a labour market containing a fixed number of identical firms with monopoly power in the product market. The $i$ th firm has a production function of the form

$$
q_{i, t}^{S}=A e_{i, t}^{\alpha},
$$

where $q_{i, t}^{S}$ is output supplied, $e_{i, t}$ is employment, $A$ and $\alpha$ are positive constants, and $0<\alpha<1$. Each firm faces a product demand function of the form

$$
q_{i, t}^{D}=\left(\frac{p_{i, t}}{p_{t}}\right)^{-\eta} \frac{y_{t}}{f}
$$

where $y_{t}$ stands for aggregate product demand (to be specified below), $f$ is the number of firms, $p_{i, t}$ is the price charged by firm $i, p_{t}$ is the aggregate price level, and $\eta$ is the price elasticity of product demand (a positive constant).

\footnotetext{
${ }^{7}$ This work is undertaken in the spirit of recent work focusing on medium-run unemployment dynamics (e.g. Dolado and Lopez-Salido (1996), Henry and Snower (1996), and Karanassou and Snower (1993, 1998a,b).

${ }^{8}$ By contrast, in the empirical natural rate models of unemployment persistence (e.g. Joyce and Wren-Lewis (1991) and Minford (1994)) - which take only temporary and permanent shocks into account - persistent shocks such as the oil price shocks and the interest rate shocks are interpreted as reflecting changes in the long-run equilibrium unemployment rate.
} 
To derive the firm's labour demand function, we observe that the firm sets its employment at the profit maximizing level, at which the marginal revenue from producing an extra unit of output is equal to the corresponding marginal cost (for a given capital stock). The marginal revenue is $M R_{i, t}=p_{i, t}\left(1-\frac{1}{\eta}\right)$. The marginal cost is $M C_{i, t}=\omega_{i, t}\left(\frac{\partial e_{i, t}}{\partial q_{i, t}}\right) \xi_{i, t}$, where $\omega_{i, t}$ is the wage paid by the firm, $\frac{\partial e_{i, t}}{\partial q_{i, t}}$ is the marginal labour requirement, and $\xi_{i, t}$ is an employment adjustment parameter. Let the employment adjustment parameter be $\xi_{i, t}=\left(e_{i, t} / \sigma e_{i, t-1}\right)^{\delta}$, where $\delta$ is a positive constant and $\sigma$ is the "survival rate," i.e. one minus the separation rate. For simplicity, we assume that the separation rate is sufficiently high (the survival rate is sufficiently low), so that $e_{i, t}>\sigma e_{i, t-1}$. The employment adjustment parameter may be interpreted in terms of training costs: $e_{i, t} / \sigma e_{i, t-1}=1+\left(h_{i, t} / \sigma e_{i, t-1}\right)$, where $h e_{i, t}$ is new hires. The training of new hires $\left(h e_{i, t}\right)$ in period $t$ is done by the incumbent employees $\left(\sigma e_{i, t-1}\right)$ in that period. The greater the ratio of new hires to incumbent employees, the greater the average training cost per employee $\left(\xi_{i, t}\right)$. When $\delta=0$ (so that $\xi_{i, t}=1$ ), the employment adjustment cost is zero; and when $\delta>0$ (so that $\xi_{i, t}>1$ ), the adjustment cost is positive.

For the production function above, the marginal product of labour (the inverse of the marginal labour requirement) is $\frac{\partial q_{i, t}}{\partial e_{i, t}}=\alpha A e_{i, t}^{-(1-\alpha)}$. Thus the marginal cost is $M C_{i, t}=\frac{\omega_{i, t}}{\alpha A} e_{i, t}^{1-\alpha} \xi_{i, t}$. Setting the marginal revenue equal to the marginal cost, we obtain the firm's (implicit) labour demand function:

$$
\frac{\omega_{i, t}}{\alpha A} e_{i, t}^{1-\alpha}\left(\frac{e_{i, t}}{\sigma e_{i, t-1}}\right)^{\delta}=p_{i, t}\left(1-\frac{1}{\eta}\right) .
$$

In the labour market equilibrium, $p_{i, t}=p_{t}$ and $\omega_{i, t}=\omega_{t}$, due to symmetry. Aggregating all the individual firms' labour demand functions and taking logarithms, so that $E_{t}=\log \left(f e_{i, t}\right)$, we obtain the following aggregate employment equation:

$$
E_{t}=a+a_{E} E_{t-1}-a_{w} w_{t}
$$

where $w_{t}=\log \left(\omega_{t} / p_{t}\right), a=\frac{\log \left(1-\frac{1}{\eta}\right)+\log (\alpha A)+\delta \log \sigma+(1-\alpha) \log f}{1+\delta-\alpha}, a_{E}=\frac{\delta}{1+\delta-\alpha}$, and $a_{w}=$ $\frac{1}{1+\delta-\alpha}$. The parameter $a_{E}$ will be called the "employment inertia coefficient." When the employment adjustment cost is zero $(\delta=0)$, the employment inertia coefficient is zero; when the adjustment cost is positive $(\delta>0)$, the employment inertia coefficient is positive as well.

Next, we derive a price equation. For this purpose, we begin by rewriting eq. (3a) in terms of the aggregate price level as follows:

$$
P_{t}=-\frac{a}{a_{w}}+W_{t}+\frac{1}{a_{w}} E_{t}-\frac{a_{E}}{a_{w}} E_{t-1},
$$

where $P_{t}=\log \left(p_{t}\right)$, and $W_{t}=\log \left(\omega_{t}\right)$. Into this equation we substitute a product market clearing condition. Since aggregate product supply is $f A e_{i, t}^{\alpha}$ and aggregate 
product demand is $y_{t}$, this product market clearing condition is $f A e_{i, t}^{\alpha}=y_{t}$. Taking $\operatorname{logs}$, defining $c=\log \left(A f^{1-\alpha}\right)$ and $Y_{t}=\log \left(y_{t}\right)$, and rearranging gives: $E_{t}=\frac{1}{\alpha} Y_{t}-\frac{c}{\alpha}$. Substituting this equation into eq. (3b) yields the following price equation:

$$
P_{t}=W_{t}+\frac{1}{\alpha a_{w}} Y_{t}-\frac{a_{E}}{\alpha a_{w}} Y_{t-1}+z
$$

where $z=-\frac{c\left(1-a_{E}\right)}{\alpha a_{w}}+\frac{a}{a_{w}}$.

Our model of wage setting behavior, follows the wage staggering literature, in the spirit of Taylor (1979)). In accord with the regular setup, suppose that each wage contract lasts for two periods and the contracts are evenly staggered. Let $\Omega_{t}$ be the $\log$ of the contract wage negotiated at the beginning of period $t$ for periods $t$ and $t+1$. Then the average wage is

$$
W_{t}=\frac{1}{2}\left(\Omega_{t}+\Omega_{t-1}\right) .
$$

Following Taylor, the contract wage is given by

$$
\Omega_{t}=\left(1-b_{1}\right) \Omega_{t-1}+b_{1} \widehat{\Omega}_{t+1}+\gamma\left[\left(1-b_{1}\right) \widehat{Y}_{t}+b_{1} \widehat{Y}_{t+1}\right]+\varepsilon_{t},
$$

where $Y_{t}$ represents aggregate demand, $\varepsilon_{t}$ is a strict white noise process, $\gamma$ represents the sensitivity of wages to aggregate demand $(\gamma>0)$, and "ح" over a variable stands for the expectation of that variable conditional on the information available at time $t-1$. The coefficient $b_{1}$ indicates how forward- or backward-looking the contract is.

In the conventional way, aggregate demand $\left(Y_{t}\right)$ is assumed to depend on real money balances $\left(M_{t}-W_{t}\right): Y_{t}=M_{t}-W_{t}+v_{t}$ where $M_{t}$ is the log of the money supply and $v_{t}$ is a shock. Following Taylor (1979), we assume that the policy rule for money supply is given by $M_{t}=(1-\theta) W_{t}$, where $\theta(0 \leq \theta \leq 1)$ represents the degree to which monetary policy is accommodating. Thus, the simple aggregate demand relation becomes

$$
Y_{t}=-\theta W_{t}+v_{t}
$$

Substituting eq. (7) into eq. (6) and taking conditional expectations, and assuming that $\Omega_{t}$ is monotonically stable, we obtain $\Omega_{t}=b_{w} \Omega_{t-1}+\varepsilon_{t}$, where $b_{w}$ is a constant: $b_{w}=\frac{d-\left[d^{2}-4 b_{1}\left(1-b_{1}\right)\right]^{1 / 2}}{2 b_{1}}$, and $d=\frac{1+0.5 \theta \gamma}{1-0.5 \theta \gamma}$. Solving and substituting into (5), we find that the average wage is

$$
W_{t}=b_{w} W_{t-1}+\frac{1}{2}\left(\varepsilon_{t}+\varepsilon_{t-1}\right) .
$$

We now combine this nominal wage equation with the price equation in order to derive a real wage equation. Substituting (7) into eq.(4), we find that the aggregate price level may be expressed as $P_{t}=\lambda_{1} W_{t}+\lambda_{2} W_{t-1}+\mu_{t}$, where $\lambda_{1}=1-\frac{\theta}{\alpha a_{w}}, \lambda_{2}=\frac{a_{E} \theta}{\alpha a_{w}}$, and $\mu_{t}=z+\frac{v_{t}}{\alpha a_{w}}-\frac{a_{E} v_{t-1}}{\alpha a_{w}}$. Using this price equation along with the nominal wage 
equation (8), the real wage may be expressed $\operatorname{as}^{9}$

$$
w_{t}=b_{w} w_{t-1}+\left(1-\lambda_{1}\right) \epsilon_{t}-\lambda_{2} \epsilon_{t-1}-\mu_{t}+b_{w} \mu_{t-1},
$$

where $w_{t}=W_{t}-P_{t}$ represents the log of real wage, and $\epsilon_{t}=\frac{1}{2}\left(\varepsilon_{t}+\varepsilon_{t-1}\right)$. This equation may be called the "wage setting equation," and the coefficient $b_{w}$ is denoted the "wage staggering coefficient."

The labour force participation decision equates the marginal return from being in the labour force with the associated marginal cost being in the labour force. For simplicity, let the per capita return (in logs) from being in the labour force be positively related to the employment probability $\left(E_{t}-L_{t}\right.$, where $L_{t}$ is the size of the labour force (in logs) ) and to the wage $\left(w_{t}\right)$. Specifically, let the return be given by $d_{1}+$ $d_{2}\left(E_{t}-L_{t}\right)+d_{3} w_{t}$, where $d_{1}, d_{2}$, and $d_{3}$ are positive constants. Regarding the cost per capita of being in the labour force, suppose that there are costs of entry into the labour force and that these costs depend positively on the ratio of new labour force entrants to incumbent members of the labour force. Accordingly, let the cost per capita (in logs) be given by $c_{1}+c_{2} L_{t}-c_{3} L_{t-1}$ (where the new labour force entrants are positively related to $L_{t}-L_{t-1}$, the number of incumbents are positively related to $L_{t-1}$, and $c_{2}>c_{3}$ ). Setting the per capita return equal to the per capita marginal cost, we obtain the following labour force participation equation:

$$
L_{t}=c+c_{w} w_{t}+c_{E} E_{t}+c_{L} L_{t-1}
$$

where $c=\frac{-c_{1}+d_{1}}{c_{2}+d_{2}}, c_{w}=\frac{d_{3}}{c_{2}+d_{2}}, c_{E}=\frac{d_{2}}{c_{2}+d_{2}}, c_{L}=\frac{c_{3}}{c_{2}+d_{2}}$. The coefficient $c_{L}$ may be called the "labour force inertia coefficient."

Finally, the unemployment rate $u_{t}$ may be approximated as the difference between the $\log$ of the labour force $L_{t}$ and the $\log$ of employment $E_{t}$ :

$$
u_{t}=L_{t}-E_{t} .
$$

The labour market system comprising the employment equation (3a), the wage setting equation (9), the labour force equation (10) and the unemployment equation (11) describes our illustrative labour market, containing various lagged adjustment processes. In the next section we proceed to the empirical evidence, and examine how these lagged adjustment processes interact with one another and with the dynamic structure of the labour market shocks to generate long swings in unemployment.

\section{An Empirical Model of the UK Labour Market}

First consider the raw data. Figure 1a describes the UK unemployment rate over the sample period. It is evident that this unemployment rate has been subject to lengthy

\footnotetext{
${ }^{9}$ Rewriting the wage equation $(8)$ as $\left(1-b_{w} B\right) W_{t}=\epsilon_{t}$, rewriting the price equation as $\left(1-b_{w} B\right) P_{t}=\left(1-b_{w} B\right)\left[\lambda_{1} W_{t}+\lambda_{2} W_{t-1}+\mu_{t}\right]$ and subtracting the latter equation from the former, yields the wage setting equation $(9)$.
} 
fluctuations, rising in step-like fashion in the mid-1970s and then again in the early 1980s, then falling in the late 1980s, rising in the early 1990s, and finally falling since 1993.

Figure 1b describes (the logs of) employment and labour force. Observe that neither of these two time series mirrors the unemployment fluctuations closely. Employment appears to be characterized by significant serial correlation, but is more responsive to the cyclical swings in national product than is the unemployment rate. Thus the long swings in unemployment are due not just to prolonged employment adjustments, but to prolonged labour supply adjustments as well. These two adjustments are captured by the labour demand and labour supply equations in the empirical model below.

Along the lines of the theoretical framework in the previous section, our empirical model of the UK labour market describes unemployment in terms of the difference between the equilibrium labour force and equilibrium employment; it explains equilibrium employment and the equilibrium real wage in terms of the intersection between a labour demand curve and a wage setting curve; and it explains the equilibrium labour force in terms of the labour supply at the equilibrium real wage. The empirical model was estimated using annual data for the sample period of 1964-97. The variables are defined in Table 1 and the estimated system in given in Table 2, where the employment equation (T1), the wage setting equation (T2), and the labour force participation equation (T3) may be viewed as empirical counterparts to equations (3a), (9), and (10) in the previous section. ${ }^{10}$

The equations were estimated using the autoregressive distributed lag (ARDL) approach to cointegration analysis, developed by Pesaran and Shin (1995), Pesaran (1997), and Pesaran, Shin and Smith (1996). According to Pesaran and Shin (1995) "...the traditional ARDL approach justified in the case of trend-stationary regressors, is in fact equally valid even if the regressors are first-difference stationary". Once the order of the ARDL has been specified, the long-run relation of the variables is given by the steady-state solution of the estimated equation.

This approach has two significant advantages over the usual one of using cointegration techniques to test for the existence of long-run relations and then to estimate the short-run dynamics and the adjustment mechanism towards the equilibrium through an error correction model. First, since our analysis aims to assess the empirical importance of lagged adjustment processes, it is useful to depict these processes in terms of coefficients of lagged endogenous variables, which can be given a straightforward

\footnotetext{
${ }^{10}$ Noting that labour and capital are not the only available factors of production and that the sample period describes the medium-run - rather than the long-run - properties of employment, there was no reason to restrict the long-run coefficient of the capital stock to unity in the labour demand equation.

In the labour supply equation, the restriction that the long-run elasticity of working age population is unity could not be rejected at the $5 \%$ size of the test.

In the wage equation, the use of the replacement ratio instead of benefits per person as an explanatory variable will only result in a renormalization of the equation.
} 
economic interpretation, as illustrated in the previous section. Second, the ARDL approach is applicable regardless of whether the regressors are $\mathrm{I}(0)$ or $\mathrm{I}(1)$, and thus does not involve the pre-testing problems that surround cointegration analysis.

The equations of the system, selected on the basis of the Akaike Information Criterion or the Schwarz Bayesian Criterion, pass the CUSUM and CUSUMSQ tests for structural stability. As shown in the misspecification tests of Table 3, the equations consist of stationary, well-specified linear combinations of the variables used. We then estimated the preferred specifications as a system using 3SLS (equations (T4)-(T6) in Table 4) in order to take into account potential endogeneity and cross equation correlation. $^{11}$

In the context of the estimated labour market system in Table 4, we now proceed with its dynamic responses to shocks with various temporal structures.

\section{Dynamic Unemployment Responses to Labour Market Shocks}

Figure 2a shows the dynamic unemployment responses to temporary shocks in the labour demand, wage setting, and labour force equations. These shocks may be interpreted as realizations of the white noise error terms in these equations. Each of the shocks is considered one at a time, occurs in year 1 and lasts for just a year. The shocks are normalized so that their immediate impact is to raise the unemployment rate by one percentage point in year $1 .{ }^{12}$ Observe that the three shocks give rise to markedly different dynamic unemployment responses. ${ }^{13}$ As summarized in Table 5, the temporary labour demand shock leads to a gradual fall of the unemployment rate, so that $90 \%$ of the initial unemployment effect has worn off after 4 years. By contrast, the temporary real wage shock at first generates a rise in the unemployment rate, followed by a gradual fall and eventually overshooting: after its initial rise unemployment falls well beneath its original level (before the occurrence of the shock), and then oscillates towards this level, completing $90 \%$ of the adjustment after 12 years. Finally, the labour supply shock leads to pronounced overshooting, and it now takes 10 years for $90 \%$ of the adjustment to work itself out.

Figure 2b illustrates the dynamic unemployment responses to MA(4) shocks in the labour demand, wage setting, and labour force equations. These five-year shocks are normalized in the same way as above. Observe that the unemployment rate now continues to rise for several years after the MA(4) shocks are initiated. It takes

\footnotetext{
${ }^{11}$ Observe that the OLS and 3SLS estimates of our labour market model are very similar.

${ }^{12}$ Naturally, in order for the unemployment rate to rise in the initial period, the labour demand shock must be negative, whereas the wage setting and labour supply shocks must be positive.

${ }^{13}$ Since the labour market system consists of equations which satisfy the stability conditions, the effects of all the shocks considered in this section gradually disappear regardless of the initial conditions, once the exogenous variables are held constant. In addition, for the purposes of computing the unemployment responses, it does not matter at what levels the exogenous variables are held constant for the following reason. Since the system is linear, the values of the exogenous variables do not affect the difference between unemployment in the presence and absence of the shock.
} 
8, 17, and 19 years for $90 \%$ of the adjustment in response to the five-year labour demand, wage setting, and labour supply shocks to work themselves out, respectively. In contrast to the temporary shocks, it is now the labour supply shock (rather than the real wage shock) that takes longest to dissipate itself.

Figures $2 \mathrm{c}$ and $2 \mathrm{~d}$ show the dynamic unemployment responses to $\mathrm{AR}(1)$ shocks with autoregressive parameters of 0.2 and 0.8 , respectively. As the figures illustrate, the greater is the $\mathrm{AR}(1)$ parameter, the smaller the tendency for overshooting in response to the labour supply shock, and the greater the persistence of the unemployment effect from a labour supply shock relative to that from a labour demand shock. For an $\mathrm{AR}(1)$ shock with autoregressive parameter 0.2 in labour demand, wage setting, and labour supply, it takes 10, 15, and 10 years, respectively, for $90 \%$ of the unemployment adjustment to have worked itself out; whereas for an AR(1) shock with autoregressive parameter 0.8 , it takes 15,23 , and 18 years, respectively.

These simulation exercises illustrate dramatically that non-permanent shocks particularly those that persist for several years - may have very prolonged effects on unemployment, after they have worked their way through the network of lagged labour market adjustment processes. We have suggested that a possible reason why these unemployment effects last so long is that the lagged adjustment processes tend to be complementary to one another, in the sense that a shock has a more prolonged influence on unemployment when the adjustment processes interact with one another than when these processes are operative in isolation. To capture these complementarities empirically, let us compare the joint influence of these processes with the sum of their individual influences.

The individual influences may be derived as follows. Our empirical model contains four lagged adjustment processes, described by the following coefficients: (i) the "employment inertia coefficients," associated with the lagged employment terms in the labour demand equation, (ii) the "wage staggering coefficients," given by the lagged wage terms in the wage setting equation, (iii) the "labour force inertia coefficients," described by the lagged labour force terms in the labour supply equation, and (iv) the "discouraged worker coefficients" given by the unemployment change term $\left(\Delta u_{t}\right)$ in the labour supply equation. We consider the influences of these individual effects in response to a particular shock: a temporary (one-period) real wage shock.

To derive how unemployment responds to this shock in the presence of the employment inertia effect alone, we simulate a labour market system that differs from the empirical model above only in that the wage staggering, labour force inertia, and discouraged worker effects are absent (viz, $w_{t-i}=w_{t}$ in the wage setting equation, $u_{t-i}=u_{t}$ and $L_{t-i}=L_{t}$ in the labour supply equation). The unemployment responses in the presence of each of the other individual lagged effects may be derived analogously. In this way, each lagged effect may be associated with a time series of unemployment responses to the temporary real wage shock.

Next we sum all these time series of unemployment responses and normalize the shock so that its immediate (first-period) impact is to raise unemployment by one 
percentage point. The resulting time series, which may be interpreted as the unemployment response when the lagged adjustment processes are operating in isolation from one another, is illustrated in Figure 3a. As shown, it takes 4 years for $90 \%$ of the initial unemployment impact to wear out. We have seen, however, that when all the lagged adjustment processes are simultaneously operative, it takes 12 years for $90 \%$ of the adjustment to work itself out. The difference between the 12-year and the 4 -year period may considered a temporal measure of the complementarities among the lagged adjustment processes.

Finally, we have suggested that the swings in unemployment may also be prolonged through the interaction between the persistence of labour market shocks and the persistence of the temporal propagation mechanism (i.e. the prolonged unemployment responses arising from the network of lagged adjustment processes). We capture this interaction empirically with reference to an MA(4) real wage shock.

To measure the individual contribution of shock persistence to unemployment persistence, we derive the time series of unemployment responses to the MA(4) wage shock in the absence of all lagged adjustment processes (viz, we set $E_{t-i}=E_{t}$ in the employment equation, $w_{t-i}=w_{t}$ in the wage setting equation, $L_{t-i}=L_{t}$ and $u_{t-i}=u_{t}$ in the labour supply equation). Next, to measure the individual contribution of the temporal propagation mechanism to unemployment persistence, we derive the time series of unemployment responses to a temporary (one-period) wage shock in the presence of all the lagged adjustment processes. Summing these two contributions - the contribution of shock persistence and of the persistence in the temporal propagation mechanism - and normalizing the shock so that its immediate (first-period) impact is to raise unemployment by one percentage point, we obtain the unemployment time series illustrated in Figure 3b. It may be interpreted as the unemployment response when the persistence of the shocks and the persistence of the temporal propagation mechanism are operating in isolation from one another. As shown in the figure, it takes 12 years for $90 \%$ of the initial unemployment impact to wear out. Yet we have seen that when the network of lagged adjustment processes interact with the persistence of the shock, it takes 17 years for $90 \%$ of the initial unemployment impact to wear out.

With this background on the role of complementarities between different lagged adjustment processes and complementarities between these adjustment processes and shock persistence, we are now in a position to examine the role of adjustment dynamics and the natural rate of unemployment in accounting for the movement of unemployment in the UK.

\section{The Role of Adjustment Dynamics and the Natural Rate of Unemployment}

Although our estimated system passes the standard econometric tests, it has a high level of aggregation, both sectorally and temporally, and thus it is wise to view it in the same light as the theoretical framework, namely, as simply illustrative of some major 
labour market adjustment processes. Within this context, we proceed to explore the degree to which the movements in UK unemployment may be attributed to changes in the NRU versus prolonged dynamic responses to persistent shocks.

Our specification of the NRU is quite standard in the empirical literature: it is the equilibrium unemployment rate at which the unemployment rate has no tendency to change, given the permanent components of the exogenous variables. In this sense, it represents the unemployment that would be achieved once all the lagged adjustment processes have been completed in response to the permanent exogenous variables. ${ }^{14}$

To derive it, we begin by expressing the estimated labour market system of Table 4 as

$$
\begin{aligned}
\Delta E_{t} & =\beta_{1}+\beta_{2} E_{t-2}+\beta_{3} w_{t}+\beta_{4} K_{t}+\beta_{5} \Delta K_{t}+\beta_{6} \Delta K_{t-1}+\beta_{7} \tau_{t}^{I}+\beta_{8} p_{t}^{o i l}, \\
\Delta w_{t} & =\beta_{9}+\beta_{10} w_{t-2}+\beta_{11} b_{t}^{s s}+\beta_{12} \Delta \tau_{t}^{I}+\beta_{13} u_{t}, \\
\Delta L_{t} & =\beta_{14}+\beta_{15} \Delta L_{t-1}+\beta_{16} L_{t-2}+\beta_{17} \Delta u_{t}+\beta_{18} w_{t}-\beta_{16} Z_{t},
\end{aligned}
$$

where $\Delta$ is the difference operator, and the $\beta$ 's are the estimated parameters. Next, we rewrite the system as follows:

$$
\begin{aligned}
& \Phi_{1} E_{t}=C_{t}^{E}+\beta_{3} w_{t} \\
& \Phi_{2} w_{t}=C_{t}^{w}+\beta_{13} u_{t} \\
& \Phi_{3} L_{t}=C_{t}^{L}+\beta_{17}(1-B) u_{t}+\beta_{18} w_{t}
\end{aligned}
$$

Here $\Phi_{1}=\left(1-B-\beta_{2} B^{2}\right), \Phi_{2}=\left(1-B-\beta_{10} B^{2}\right), \Phi_{3}=1-\left(1+\beta_{15}\right) B-\left(\beta_{16}-\beta_{15}\right) B^{2}$, where $B$ is the backshift operator; furthermore $C_{t}^{E}=\beta_{1}+\beta_{4} K_{t}+\beta_{5} \Delta K_{t}+\beta_{6} \Delta K_{t-1}+$ $\beta_{7} \tau_{t}^{I}+\beta_{8} p_{t}^{\text {oil }}, C_{t}^{w}=\beta_{9}+\beta_{11} b_{t}^{s s}+\beta_{12} \Delta \tau_{t}^{I}$, and $C_{t}^{L}=\beta_{14}-\beta_{16} Z_{t}$. Using equations (12a)-(12c) together with the definition $u_{t}=L_{t}-E_{t}$, we derive the following reduced form unemployment rate equation:

$$
\begin{aligned}
& \left\{\Phi_{1} \Phi_{2}\left[\Phi_{3}-\beta_{17}(1-B)\right]+\beta_{13}\left(\beta_{3} \Phi_{3}-\beta_{18} \Phi_{1}\right)\right\} u_{t} \\
= & -\Phi_{3} \Phi_{2} C_{t}^{E}+\left(\beta_{18} \Phi_{1}-\beta_{3} \Phi_{3}\right) C_{t}^{w}+\Phi_{1} \Phi_{2} C_{t}^{L} .
\end{aligned}
$$

If the lagged adjustment processes (governing the movements of the endogenous variables) had worked themselves out in each time period, $B$ would be equal to unity in equations (12a-12c) and the endogenous variables would then be

$$
\widehat{E}_{t}=\frac{C_{t}^{E}+\beta_{3} \widehat{w}_{t}}{-\beta_{2}}
$$

\footnotetext{
${ }^{14}$ Clearly, these adjustment processes refer to the endogenous variables of the model, not the exogenous ones, such as the capital stock. Thus, the estimate of the NRU inevitably depends on the choice of endogenous and exogenous variables. Regardless of how these sets of variables are chosen, empirical labour market system models generally contain exogenous variables that move in accordance with some (unspecified) adjustment processes. The levels of these variables are taken as given at each point in time when the NRU is computed.
} 


$$
\begin{aligned}
\widehat{w}_{t} & =\frac{C_{t}^{w}+\beta_{13} \widehat{u}_{t}}{-\beta_{10}}, \\
\widehat{L}_{t} & =\frac{C_{t}^{L}+\beta_{18} \widehat{w}_{t}}{-\beta_{16}} .
\end{aligned}
$$

The corresponding unemployment rate is

$$
\widehat{u}_{t}=\frac{\beta_{2} \beta_{10} C_{t}^{L}+\left(\beta_{16} \beta_{3}-\beta_{2} \beta_{18}\right) C_{t}^{w}-\beta_{16} \beta_{10} C_{t}^{E}}{\beta_{2} \beta_{18} \beta_{13}-\beta_{16} \beta_{3} \beta_{13}-\beta_{2} \beta_{10} \beta_{16}}
$$

which is simply the long-run solution of the dynamically stable ${ }^{15}$ "reduced form" unemployment rate eq. (13). Therefore, eq. (15) can be interpreted as a cointegrated vector, i.e $\left[u_{t}-\right.$ right hand side of $\left.(15)\right] \sim I(0)$.

The unemployment rate $\widehat{u}_{t}$ is not, however, the natural rate of unemployment, since the movements in the NRU are meant to reflect permanent labour market shocks but not transitory ones. Thus, to derive the NRU we need to identify the permanent components of the exogenous variables in eq. (15), and then compute the corresponding unemployment rate. Our estimates of the NRU will inevitably reflect our interpretation of which changes in the exogenous variables were permanent and which were temporary. Figures 4 describe the time series of (the logs of) the exogenous variables.

The real oil price $\left(p_{t}^{\text {oil }}\right)$ and the indirect tax rate $\left(\tau_{t}^{I}\right)$ may be interpreted as $\mathrm{I}(0)$, so that fluctuations in these exogenous variables are taken to be temporary and thus

\footnotetext{
${ }^{15}$ Eq. (13) is dynamically stable since it can be shown that the polynomial

$$
\Phi_{1} \Phi_{2}\left[\Phi_{3}-\beta_{17}(1-B)\right]+\beta_{13}\left(\beta_{3} \Phi_{3}-\beta_{18} \Phi_{1}\right)
$$
}

satisfies the stability conditions. To see this note that $\Phi_{1}, \Phi_{2}$, and $\Phi_{3}$ are polynomials in the $B$ operator which satisfy the stability conditions. In particular, observe that for $\Phi_{3}$ these conditions are as follows:

$$
\begin{aligned}
\left(1+\beta_{15}\right)+\left(\beta_{16}-\beta_{15}\right) & <1 \\
-\left(1+\beta_{15}\right)+\left(\beta_{16}-\beta_{15}\right) & <1 \\
-\left(\beta_{16}-\beta_{15}\right) & <1
\end{aligned}
$$

Using the above, and taking into account that our estimated $\beta_{17}$ is negative, it is not difficult to see that $\left[\Phi_{3}-\beta_{17}(1-B)\right]$ also satisfies the stability conditions, namely that:

$$
\begin{aligned}
\left(\frac{1+\beta_{15}-\beta_{17}}{1-\beta_{17}}\right)+\left(\frac{\beta_{16}-\beta_{15}}{1-\beta_{17}}\right)<1 \\
-\left(\frac{1+\beta_{15}-\beta_{17}}{1-\beta_{17}}\right)+\left(\frac{\beta_{16}-\beta_{15}}{1-\beta_{17}}\right)<1 \\
-\left(\frac{\beta_{16}-\beta_{15}}{1-\beta_{17}}\right)<1
\end{aligned}
$$

Furthermore, note that (i) products of polynomials in $B$ which satisfy the stability conditions will also be stable, and (ii) linear combinations of polynomials in $B$ which satisfy the stability conditions will in general be stable (see Abadir and Taylor (1999)). Therefore eq. (13) is dynamically stable. 
not part of the NRU. Thus, in computing the NRU, these exogenous variables are assumed to follow ARMA stochastic processes and, consequently, their simulated time path converges to the unconditional mean of the ARMA equation fitted to the specific data series. ${ }^{16}$ Observe, however, that the fluctuations in these variables are quite persistent: the oil price shock lasted for over a decade, as did the second indirect tax shock.

By contrast, the other exogenous variables - the capital stock $\left(K_{t}\right)$, the population $\left(Z_{t}\right)$, and social security benefits $\left(b_{t}^{s s}\right)$ - may all be interpreted as $\mathrm{I}(1)$ processes. We capture their permanent components by using a Hodrick Prescott (HP) filter, and we use the HP smoothed series in the computation of the NRU. This procedure is broadly in accord with the conventional wisdom on the determinants of the NRU. Our only exception to this treatment of the exogenous variables concerns the growth rate of the capital stock. It is not reasonable to believe - particularly in the light of post-sample experience - that the growth rate of the capital stock follows a sharply declining trend into the indefinite future. Thus we make the common, plausible assumption that the downward blip in this growth rate over the the 1991-97 period (pictured in Fig. 4c) was temporary. Accordingly, our HP smoothed series of the capital stock presupposes that the growth rate of the capital stock $\left(\Delta K_{t}\right)$ remains constant at its 1990 value during the period 1990-97. ${ }^{17}$

Substituting the above-mentioned permanent components of the exogenous variables (pictured in Figures 4) into the unemployment equation (15), we obtain the NRU trajectory shown in Figure 5. Observe that this NRU is reasonably stable through time. It remained around $3 \%$ until the beginning of the 1970 s, it rose gradually to $6 \%$ in the mid-1980s, and finally fell back to around $4 \%$ by the mid-1990s.

Conducting standard unit root tests, we find that the NRU follows a stationary process. ${ }^{18}$ Whereas the predicted unemployment rate (13) and the fully adjusted unemployment rate (15) can both be shown to be $\mathrm{I}(1)$, the NRU is $\mathrm{I}(0)$. In this way, we reconcile two findings that appear to conflict with one another: On the one hand, the medium-term movements of unemployment (extending over periods of several decades) - in the UK as in many other European countries - generally follow a non-

${ }^{16}$ Following the standard Box-Jenkins approach we estimated the following autoregressions:

$$
\begin{aligned}
& \tau_{t}^{I}= \begin{array}{l}
0.03 \\
(0.01)
\end{array}+\begin{array}{l}
1.25 \tau_{t-1}^{I}- \\
(0.15)
\end{array}-\begin{array}{l}
0.44 \tau_{t-2}^{I} \\
(0.15)
\end{array}+\varepsilon_{1 t}, \varepsilon_{1 t} \sim \text { iid }\left(0, \sigma_{1}^{2}\right), \\
& p_{t}^{\text {oil }}=\begin{array}{l}
1.18 \\
(0.18)
\end{array} \begin{array}{l}
0.43 p_{t-1}^{\text {oil }} \\
(0.08)
\end{array}+\begin{array}{l}
0.69 d_{t} \\
(0.10)
\end{array}+\varepsilon_{2 t}, \varepsilon_{2 t} \sim \text { iid }\left(0, \sigma_{2}^{2}\right),
\end{aligned}
$$

where $d_{t}$ is a dummy variable equal to one during 1974-1985, zero otherwise, and captures the persistent oil price shock (to compute the NRU we set $d_{t}=0$ ).

${ }^{17}$ In particular, to capture the permanent component of the capital stock we (i) set $\Delta K_{t}$ constant at its 1990 value during the period 1990-97, (ii) use the HP filter to obtain the smoothed series $\left(\Delta K_{t}^{H P}\right)$, and (iii) generate the smoothed capital stock series by using the identity $K_{t}^{H P}=\Delta K_{t}^{H P}+K_{t-1}^{H P}$.

${ }^{18}$ In particular, using an Augmented Dickey-Fuller test we reject the null of a unit root at any conventional significance level $\left(\mathrm{ADF}^{3}=-3.564[\right.$ Prob. $\left.=0.006]\right)$. 
stationary process; on the other, the long-run fully adjusted unemployment rate must be stationary, since unemployment neither disappears nor becomes universal with the passage of time.

Our empirical analysis shows that the movements of the NRU did little to account of the two large swings in the UK unemployment rate over the post-war period - the doubling of this rate over the first half of the 1980s and its falling back in the second half, followed by its rise and fall in the 1990s - as shown in Figure 5. Instead, our analysis suggests, these swings are the outcome of prolonged dynamic responses to persistent shocks.

\section{Concluding Thoughts}

In the light of the chain reaction theory of unemployment, we interpret the long-lasting deviations of UK unemployment from its empirical natural rate as the outcome of the interaction between persistent shocks and temporal propagation mechanisms. These propagation mechanisms, we have argued, arise from the complementary interactions among lagged labour market adjustment processes. The labour market shocks that have driven the temporal propagation mechanisms have been largely non-recurrent and are well-known. The first significant rise of UK unemployment in the mid-1970s came at the time of the first oil price shock; the next large increase took place in the early 1980s in the aftermath of the second oil price shock; the third occurred in the early 1990s in the wake of high interest rates and correspondingly low investment activity following German unification. There were of course other shocks occurring at these times as well (e.g. contractionary macroeconomic policies, skill-biased technological change, the expansion of international trade). We argue that such shocks drove UK unemployment not primarily because they raised the static equilibrium unemployment rate, but because they led to a cumulation of very long adjustment processes.

We believe that this theme applies to various other European economies as well. ${ }^{19}$ The conventional economic explanation of the European unemployment problem rests heavily on static reasoning. The long climb of the overall European unemployment rate over the 25 years is alleged to reflect a gradual rise of the empirically identifiable natural rate of unemployment.

A difficulty with this interpretation is that it is not easy to identify the factors that have driven the European natural rate upwards. In the 1970s, the increase in European unemployment was plausibly attributed to demographic changes (particularly the influx of women and young people into the labour market), a rise in unionization, increases in the prices of oil and other raw materials, increases in unemployment benefits and related welfare entitlements, more stringent job security legislation and other labour market regulations. But these could not have been dominant in pushing European unemployment upwards in the 1980s and 1990s, when real oil prices, union

\footnotetext{
${ }^{19}$ See Henry and Snower (1996).
} 
density, unemployment benefit entitlements, and labour market regulations either remained stable or declined. On this account, the later unemployment increase has commonly been attributed to other factors, such as rising interest rates, increasing tax rates, or long delayed responses to the expansion of welfare states in the 1960s and 1970s. With 20-20 hindsight it is of course always possible to find some plausible suspects that might be responsible for the growing unemployment problem, but the selective nature of this exercise has struck many observers as unsatisfactory.

Our approach avoids this difficulty since it is not difficult to identify the nonrecurrent, persistent shocks that can initiate a long-lasting chain reaction of unemployment effects.

Moreover, our approach helps explain a long-standing empirical puzzle about the time series properties of unemployment. The unemployment rates of most European countries - including the UK - follow an I(1) process over the postwar period. Over much longer spans of time, however, we know that these rates must be $\mathrm{I}(0)$, since unemployment rates never tend to $0 \%$ or $100 \%$. One of the big challenges in unemployment theory is to provide an explanation that reconciles the I(1) property of unemployment rates in the medium run with their $\mathrm{I}(0)$ property in the long run.

The natural rate models explain the I(1) medium-run behavior by relating the unemployment rate to exogenous variables (such as union density or interest rates) that follow I(1) processes, but they shed no light on the long-run properties of the unemployment time path. In that analytical framework, the unemployment rate trends upwards when the underlying exogenous variables are trended themselves. The hysteresis models, by contrast, explain the I(1) movements of unemployment by appeal to the unit root of the unemployment process; but they, too, offer no account of why unemployment is $\mathrm{I}(0)$ in the long-run.

Our analysis points to a different course. It identifies a NRU and a long-run unemployment equilibrium that are stable through time and thus follows an $\mathrm{I}(0)$ process - in line with our knowledge that unemployment is stochastically stationary in the long run. But at the same time our analysis also suggests how the effects of persistent shocks, operating through interacting lagged adjustment processes, may have very prolonged effects on unemployment - moving unemployment along a time path that follows an $\mathrm{I}(1)$ process.

It may be argued that, due to the persistence of the shocks and the persistence of their after-effects, the unemployment rate may look as if it is unstable or trending upwards over a span of one or two decades, when it is actually just following a medium-run trajectory that diverges substantially from the stochastically stable long-run equilibrium unemployment rate. It is possibly on this account that the unemployment rate appears to follow an I(1) process over sample periods of a few decades - the sample periods usually considered in the empirical studies of the natural rate and hysteresis - whereas it is trendless and stationary in the much longer run.

Finally, it is important to note that our analysis should not be discounted as merely a "reinterpretation" of UK unemployment movements. How we interpret the 
unemployment fluctuations has far-reaching policy implications. If, at one extreme, the fluctuations reflect primarily changes in the empirically identifiable natural rate representing the equilibrium unemployment rate that is achieved once all the lagged adjustment processes have worked themselves out - then policy makers should focus attention on measures that influence the NRU; by the same token, measures that just affect the labour market's speed of response to shocks are largely irrelevant to the task of dealing with the unemployment problem. If, at the other extreme, the NRU is reasonably stable through time and the lengthy fluctuations are due primarily to prolonged adjustments to persistent shocks, then measures which affect the adjustment speed of the labour market are central to the management of unemployment, even if these measures have little impact on the NRU.

Most of the recent empirical studies of the UK labour market (such as Minford (1994) and Joyce and Wren-Lewis (1991)) tell a story that lies much closer to the first than the second. Our empirical model is a preliminary attempt to re-examine this story. It suggests that lagged labour market adjustment processes - particularly when they interact with each other and with persistent labour market shocks - have an important role to play in explaining the long swings of UK unemployment. 


\section{References}

Abadir, Karim M., and Robert A. M. Taylor (1999), "On the Definitions of (Co)integration", Journal of Time Series Analysis, 20(2), 129-139.

Bean, Charles R. (1994), "European Unemployment: A Survey", Journal of Economic Literature, 32, June, 573-619.

Bentolila, Samuel, and Giuseppe Bertola (1990), "Firing Costs and Labour Demand: How Bad is Eurosclerosis?" Review of Economic Studies, 57(3), 381-402.

Bentolila, Samuel, and Gilles Saint-Paul (1994), "A Model of Labour Demand with Linear Adjustment Costs," Labour Economics, 1, 303-326.

Bertola Giuseppe (1990), "Job Security, Employment and Wages," European Economic Review, 34, 851-886.

Blanchard, Olivier, and Lawrence Summers (1986), "Hysteresis and the European Unemployment Problem," NBER Macroeconomics Annual, vol. 1, Cambridge, Mass: MIT Press, 15-77.

Chen, Yu-Fu, Dennis J. Snower, and Gylfi Zoega (1997), "Supply Shocks, and the Effect of Firing Costs on Hiring and Firing," mimeo.

Diaz, Pilar and Dennis J. Snower (1996), "Employment, Macroeconomic Fluctuations and Job Security," CEPR Discussion Paper No. 1430.

Dolado, J., and Lopez-Salido, D. (1996), "Supply-Side Shocks and Hysteresis: An Empirical Analysis of the Spanish Labour Market," CEPR Discussion Paper No. 1334.

Henry, S.G.B., and Dennis J. Snower (1996), Economic Policies and Unemployment Dynamics in Europe, Washington, D.C.: International Monetary Fund.

Joyce, M., and S. Wren-Lewis (1991), "The Role of the Real Exchange Rate and Capacity Utilisation in Convergence to the NAIRU," Economic Journal, 101, 497-506.

Karanassou, Marika, and Dennis J. Snower (1993), "Explaining Disparities in European Unemployment Dynamics," Rivista di Politica Economica, No. 2, 37-62.

Karanassou, Marika, and Dennis J. Snower (1998a), "How Labour Market Flexibility Affects Unemployment: Long-Term Implications of the Chain Reaction Theory," Economic Journal, May, 108, 832-849.

Karanassou, Marika, and Dennis J. Snower (1998b), "The Chain Reaction Theory of Unemployment: How Unemployment Moves in the Medium Run," mimeo.

Layard, Richard, Stephen Nickell, and Richard Jackman (1991), Unemployment: Macroeconomic Performance and the Labour Market, Oxford: Oxford University Press.

Lindbeck, Assar, and Dennis J. Snower (1989), "Macroeconomic Policy and Insider Power," American Economic Review, May, 79, 370-376.

Minford, Patrick (1994), "Deregulation and Unemployment - The UK Experience," Swedish Economic Policy Review, 1, 113-141.

Nickell, Stephen (1995), "Wages, Unemployment, and Population Change," in Christophides, L., E. K. Grant, and R. Swindinsky (eds.), Aspects of Labour Market Behaviour, Toronto: University of Toronto Press.

Pesaran, M. Hashem, and Yongcheol Shin (1995), "An Autoregressive Distributed 
Lag Modelling Approach to Cointegration Analysis," Working Paper No. 9514, Department of Applied Economics, University of Cambridge.

Pesaran, M. Hashem, Yongcheol Shin, and Richard Smith (1996), "Testing for the Existence of a Long-Run Relationship," Working Paper No. 9645, CREST, Institut National de la Statistique et des Etudes Economiques.

Pesaran, M. Hashem (1997), "The Role of Economic Theory in Modelling the Long Run," Economic Journal , 107(440), Jan., 178-191.

Taylor, John B. (1979), "Staggered Wage Setting in a Macro Model," American Economic Review, 69, May, 108-113. 
Figure 1a

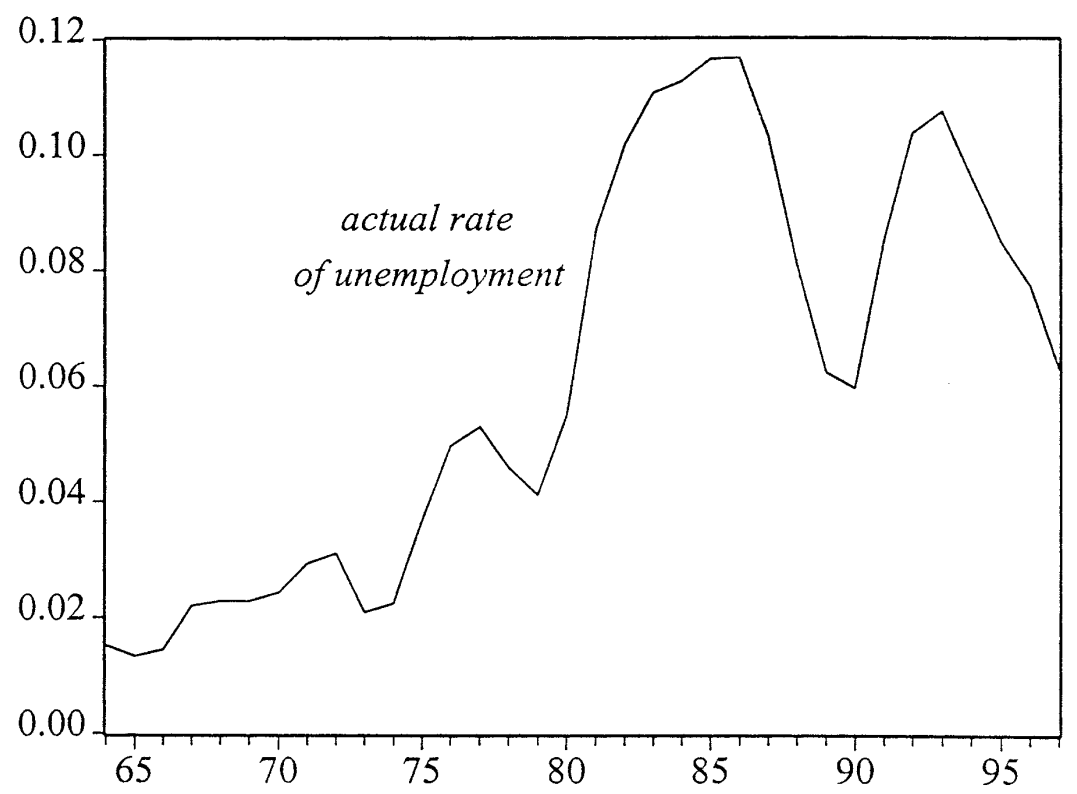

Figure 1b

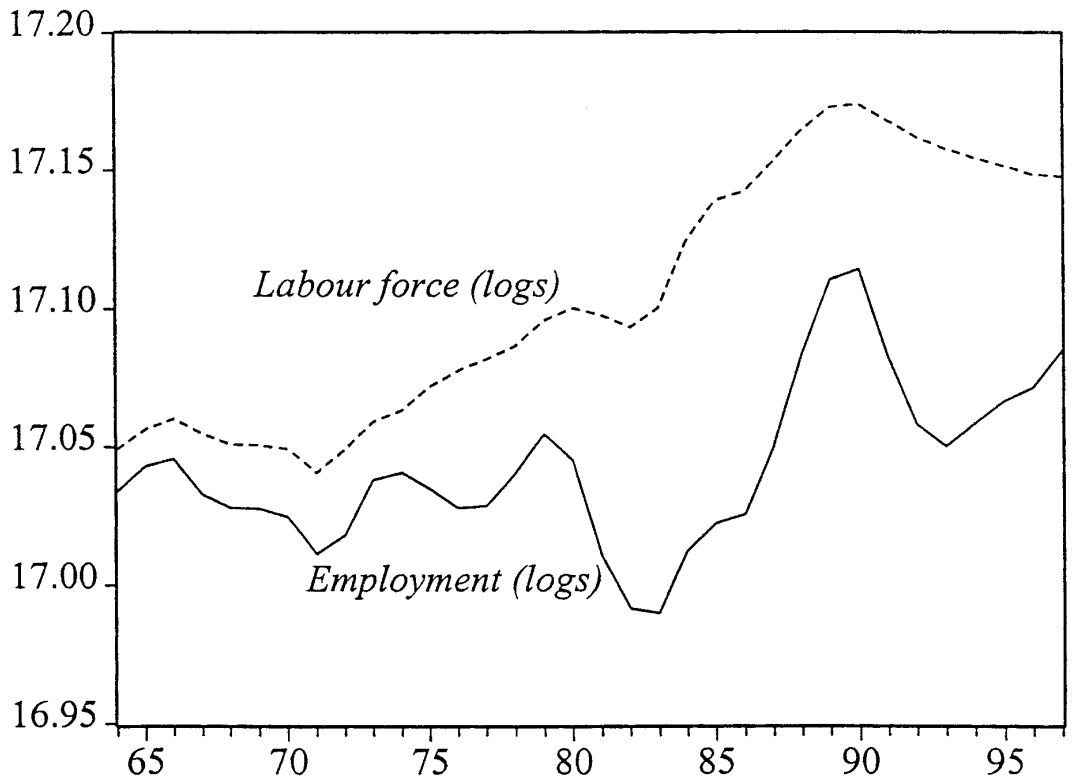


Figure 2a

Unemployment Trajectories in Response

to Temporary Shocks

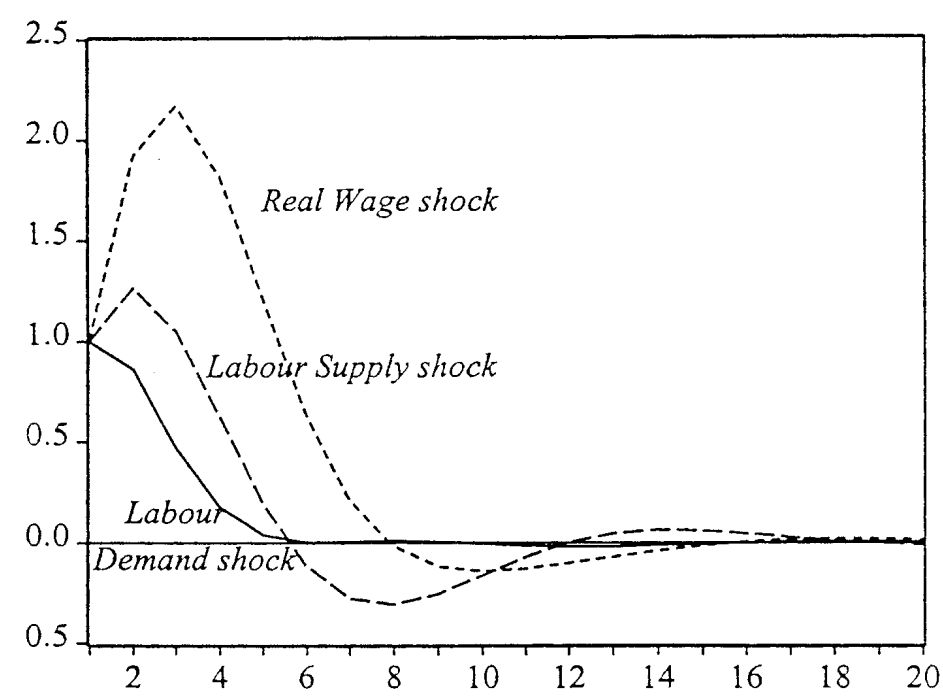

Figure 2b

Unemployment Trajectories in Response

to MA(4) Shocks

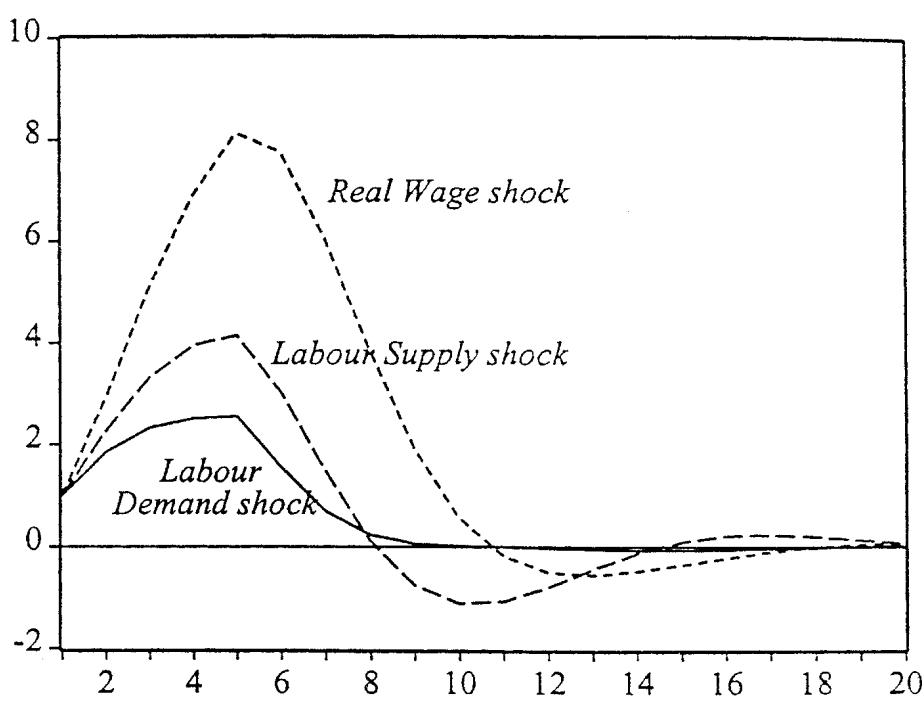

Figure 2c

Unemployment Trajectories in Response to AR(1) Shocks (Autoregressive Parameter 0.2)

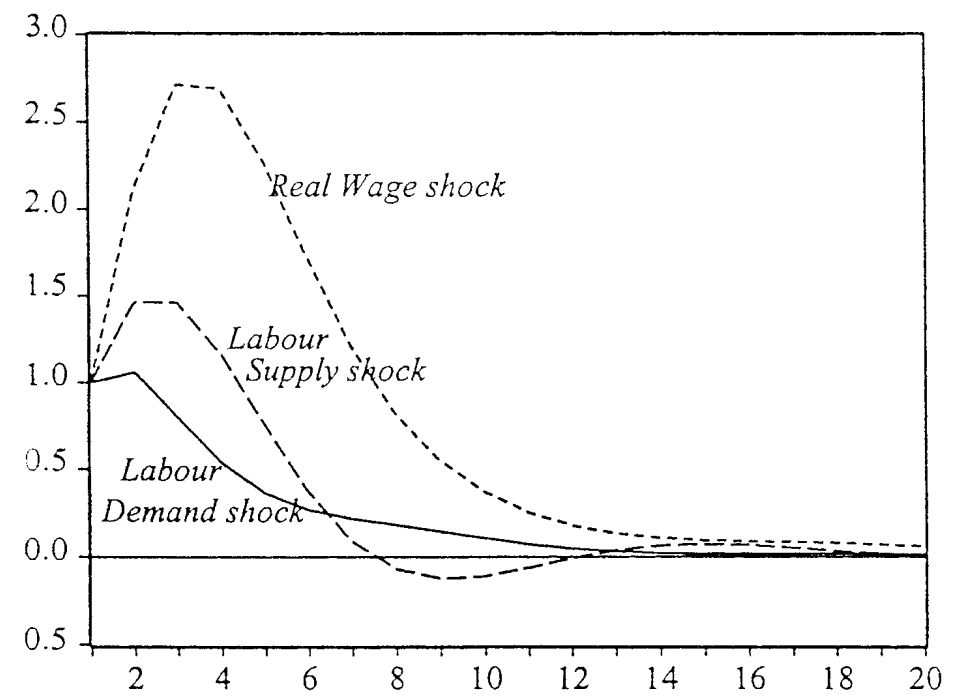


Figure 2d

Unemployment Trajectories in Response

to AR(1) Shocks (Autoregressive Parameter 0.8)

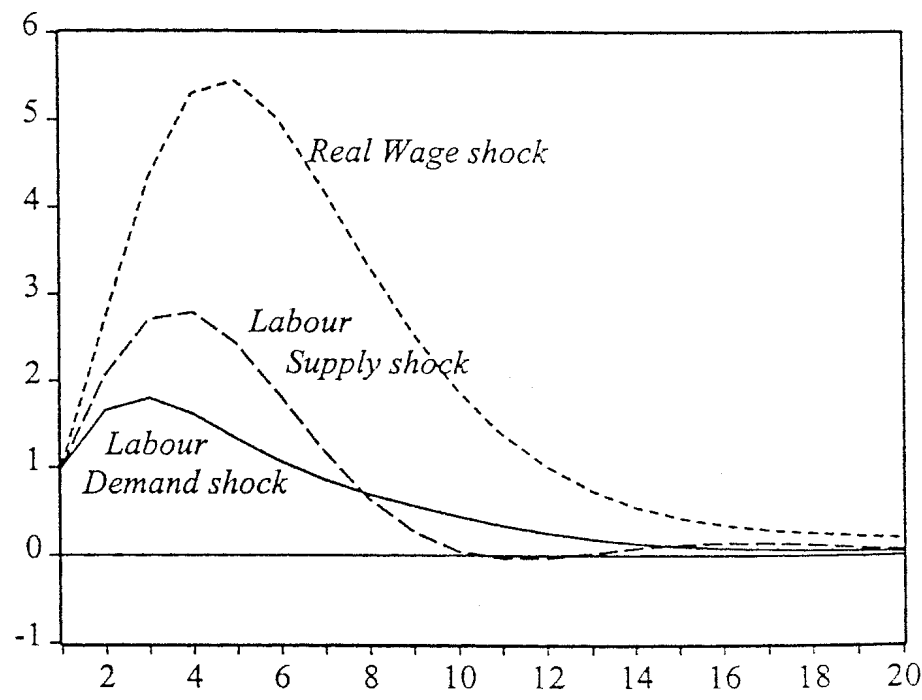

Figure 3a

Complementarities of lagged adjustment processes

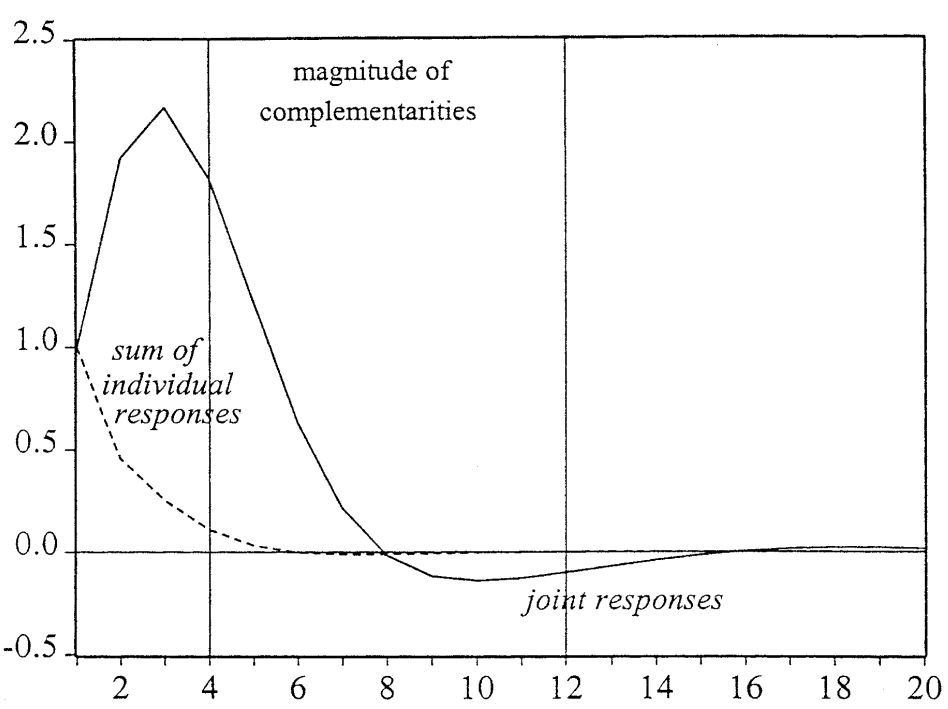

Figure $3 b$

Complementarities between shock persistence and persistence of temporal propagation mechanisms

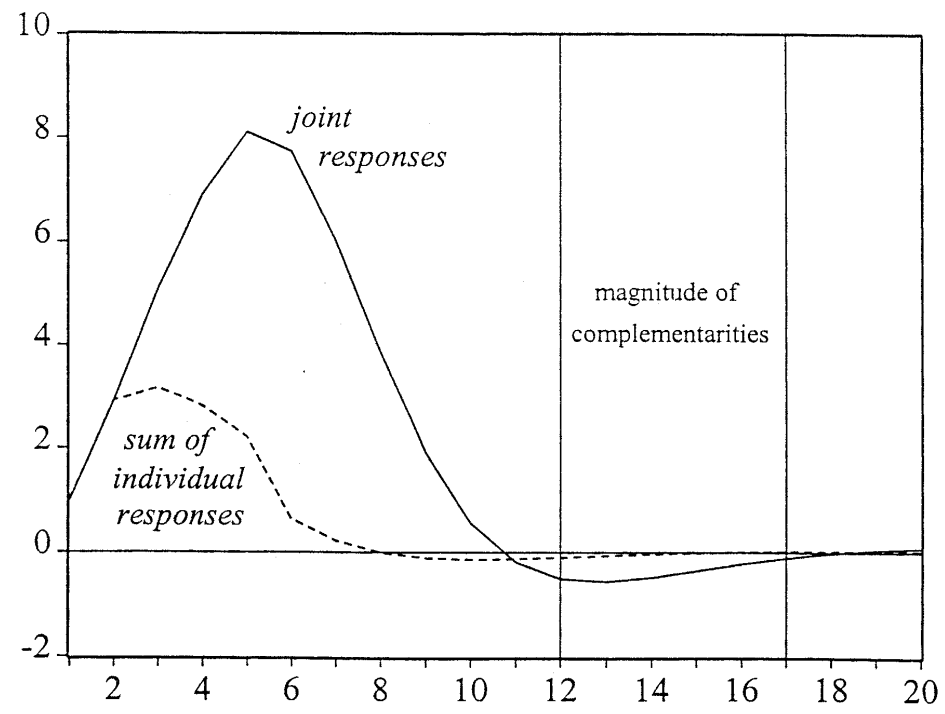


Figure 4a

Working age population (logs)

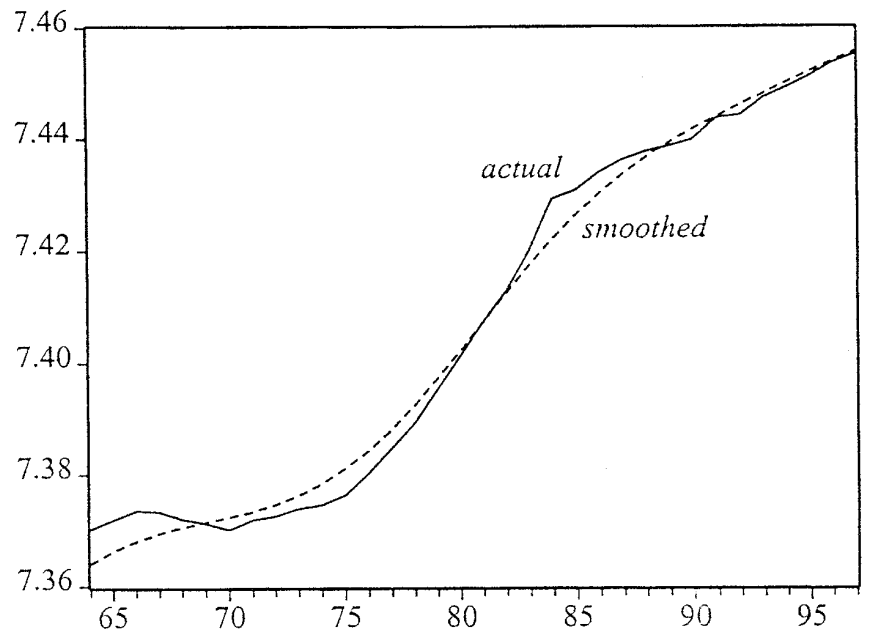

Figure $4 c$

Growth rate of capital stock

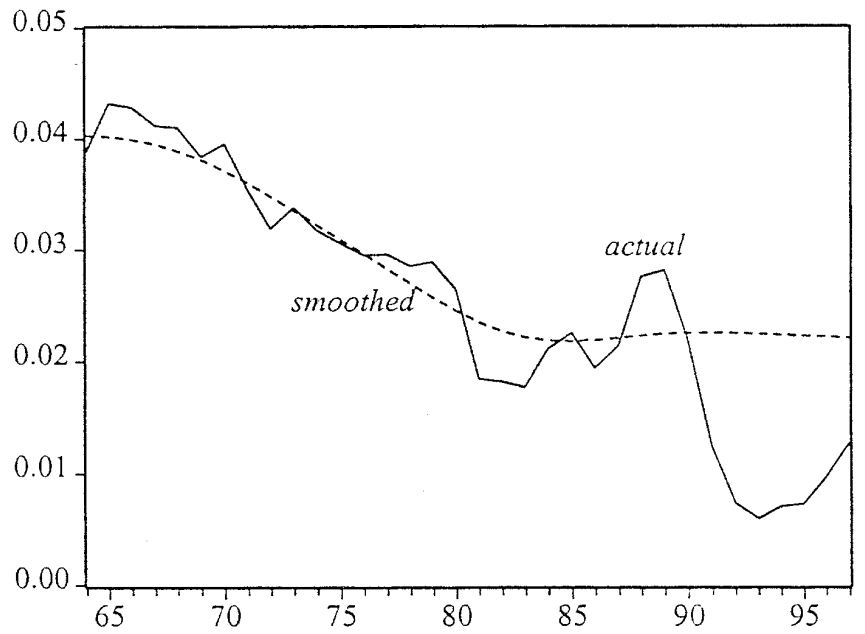

Figure $4 \mathrm{e}$

Real oil price (logs)

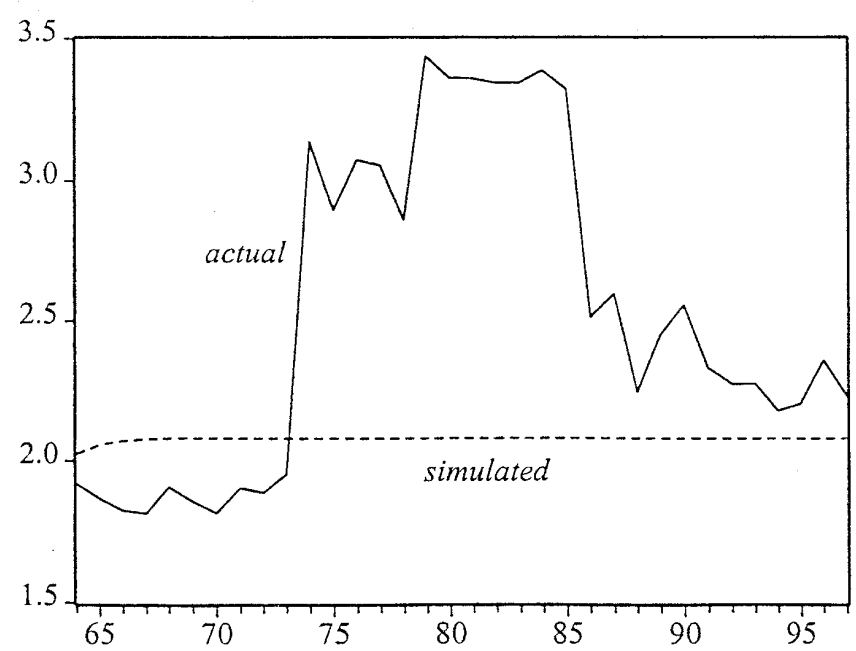

Figure $4 b$

Social security benefits per person (logs)

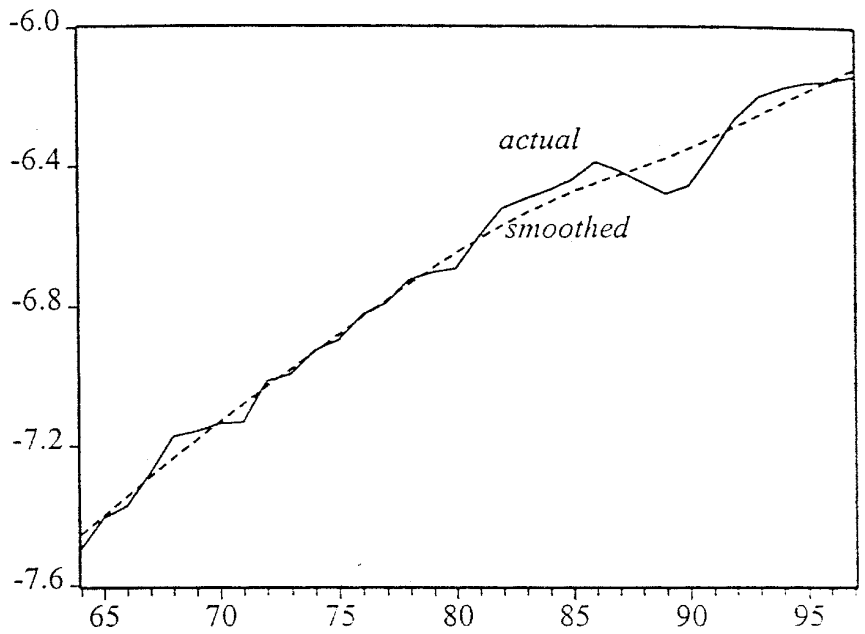

Figure $4 \mathrm{~d}$

Capital stock (logs)

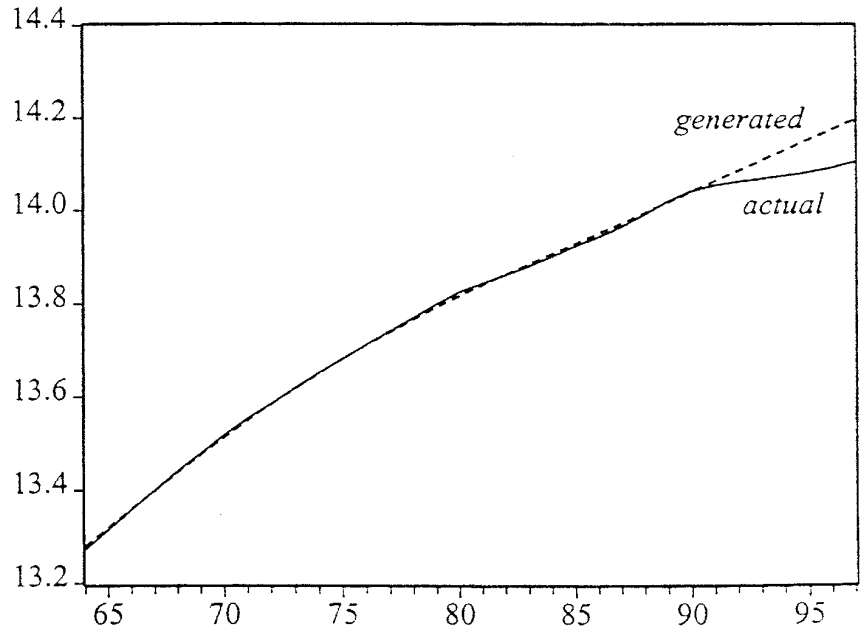

Figure 4f

Indirect tax rate

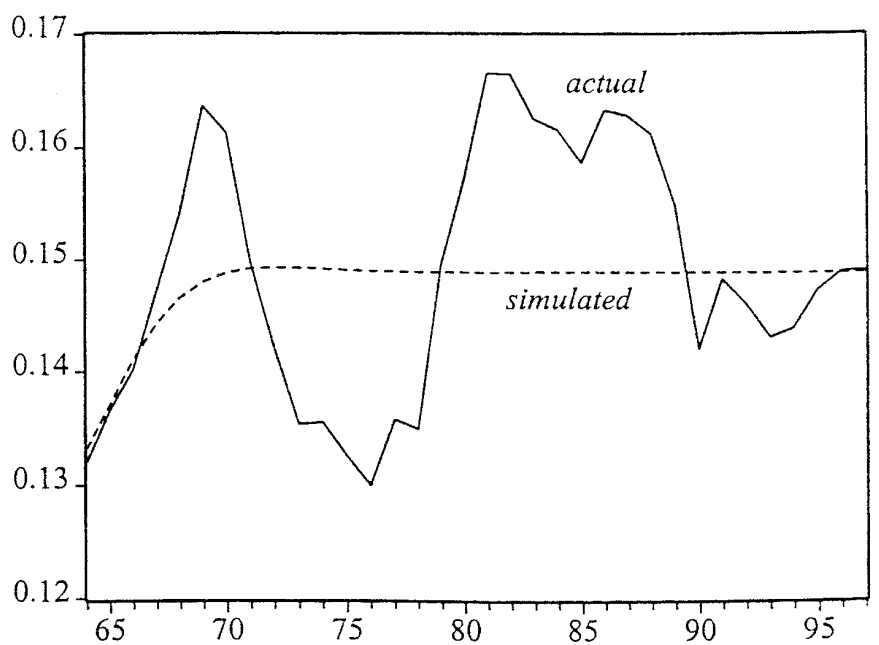


Figure 5

Actual and Natural Unemployment Rates

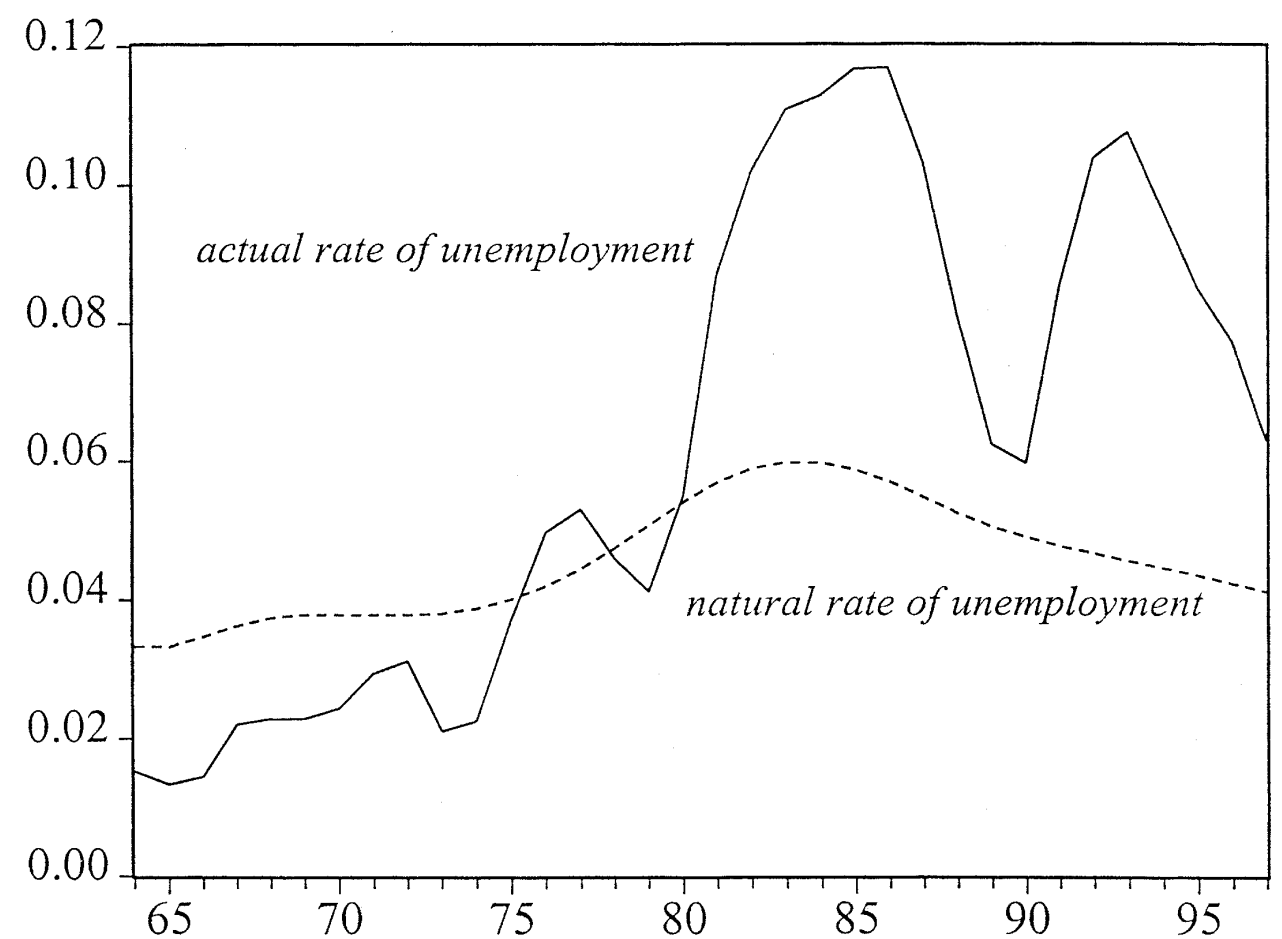




\begin{tabular}{|ll|}
\hline \multicolumn{2}{|c|}{ Table 1: Definitions of variables } \\
\hline$E_{t}:$ log of employment \\
$L_{t}:$ log of labour force \\
$u_{t}:$ unemployment rate $\left(u_{t}=L_{t}-E_{t}\right)$ \\
$w_{t}:$ log of real compensation per person employed \\
$K_{t}:$ log of real capital stock \\
$b_{t}^{s s}:$ log of real social security benefits per person \\
$\tau_{t}^{I} \quad:$ indirect taxes as a \% of GDP \\
$p_{t}^{\text {oil }}:$ log of real oil price \\
$Z_{t} \quad:$ log of working age population \\
\hline Nominal variables were deflated using the GDP deflator \\
Sources: OECD, IFS, Datastream \\
\hline
\end{tabular}

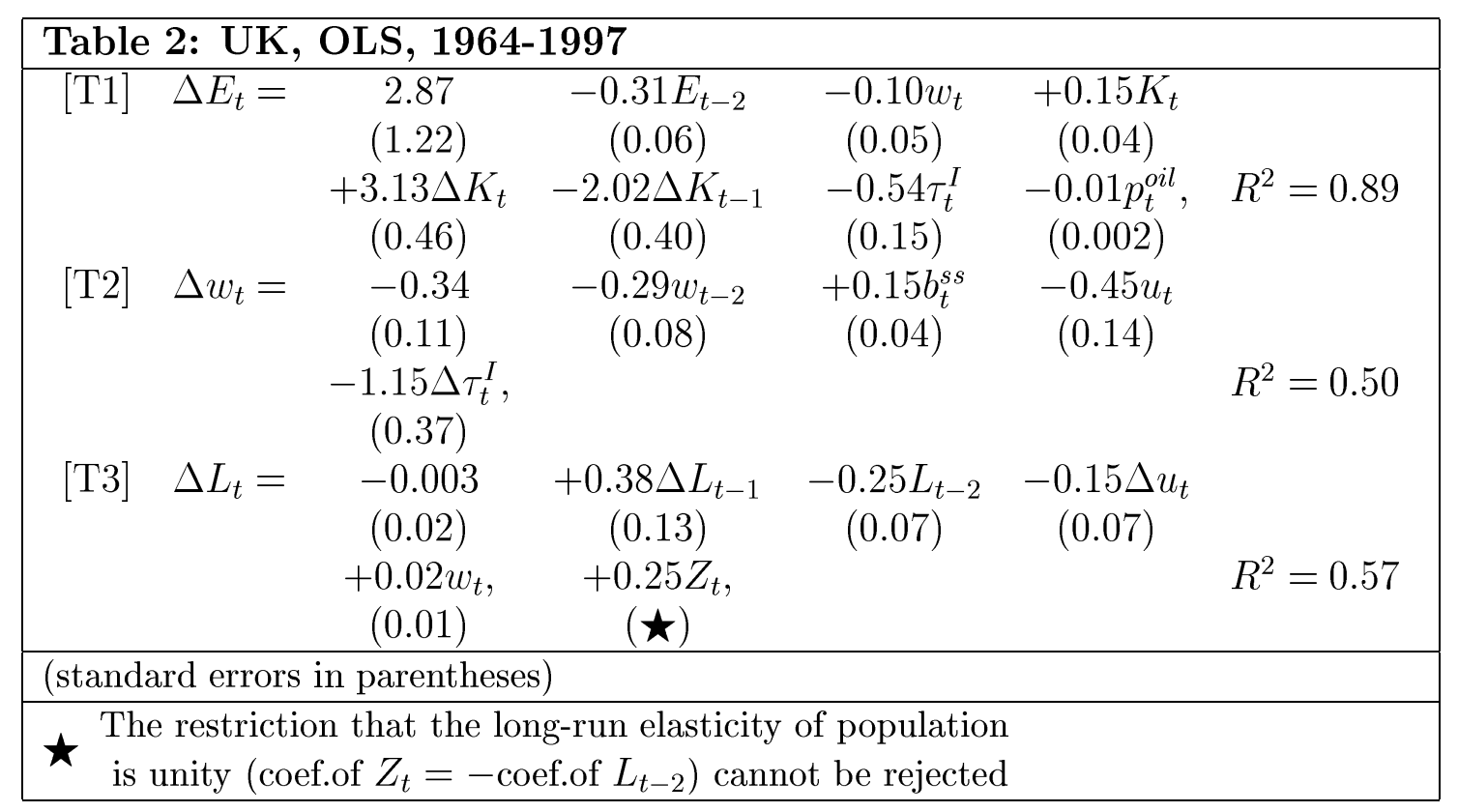




\begin{tabular}{|rccc|}
\hline \multicolumn{4}{|c|}{ Table 3: Misspecification tests } \\
\hline Equation $\rightarrow$ & {$[\mathbf{T 1}]$} & {$[\mathbf{T 2}]$} & {$[\mathbf{T 3}]$} \\
SC $\left[\chi^{2}(1)\right]$ & 1.33 & 0.25 & 0.28 \\
LIN $\left[\chi^{2}(1)\right]$ & 0.33 & 0.23 & 0.67 \\
NOR $\left[\chi^{2}(2)\right]$ & 0.28 & 1.43 & 0.73 \\
HET $\left[\chi^{2}(1)\right]$ & 1.17 & 1.09 & 0.82 \\
ARCH $\left[\chi^{2}(1)\right]$ & 0.59 & 1.09 & 0.29 \\
\hline $5 \%$ critical values: & $\chi^{2}(1)=3.84$ \\
& $\chi^{2}(2)=5.99$. \\
\hline
\end{tabular}

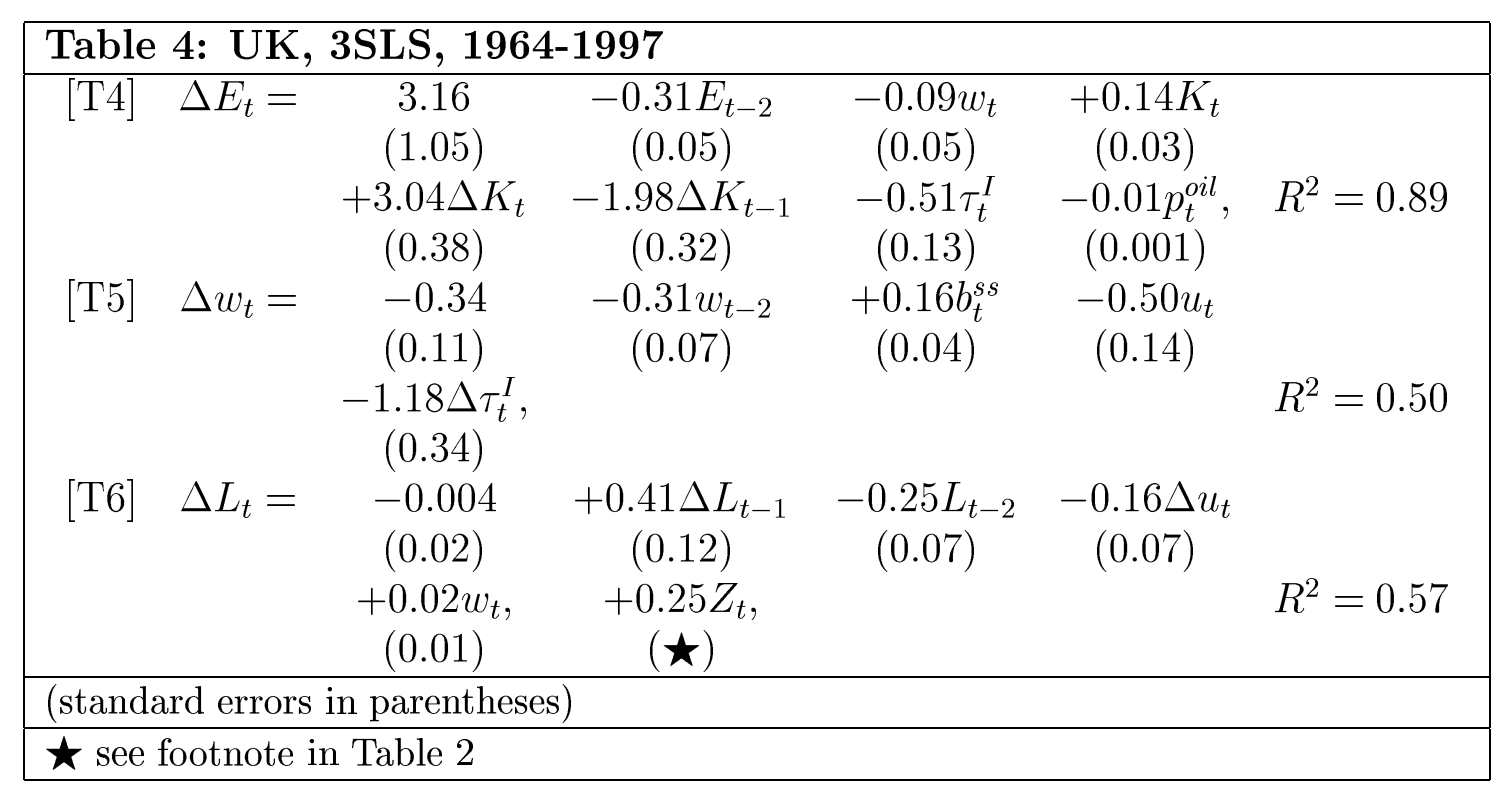

Table 5: Number of Years Until 90\% of the Initial Unemployment Effect has Worn Off

\begin{tabular}{|cccc|}
\hline Shocks & Labour Demand & Real Wage & Labour Supply \\
Temporary & 4 & 12 & 10 \\
MA $(4)$ & 8 & 17 & 19 \\
$\operatorname{AR}(1), \rho=0.2$ & 10 & 15 & 10 \\
$\operatorname{AR}(1), \rho=0.8$ & 15 & 23 & 18 \\
\hline
\end{tabular}

